УДК 378.4

DOI: 10.36718/2500-1825-2020-1-126-133

А.А. Терскова

\title{
ИЗ ИСТОРИИ СТАНОВЛЕНИЯ КРАСНОЯРСКОГО ГОСУДАРСТВЕННОГО УНИВЕРСИТЕТА
}

\section{A.A. Terskova}

\section{FROM THE HISTORY OF THE FOUNDADION OF KRASNOYARSK STATE UNIVERSITY}

50-7о-е годы XX в. были годами экономического роста и процветания Красноярского края. В этот период в регионе строились крупные промышленные предприятия, составляющие основу российской промышленности и сегодня, такие как Красноярская ГЭС, Норильский горно-металлургический комбинат, Красноярский алюминиевый завод имени В.И. Ленина. Расширялась сеть научно-исследовательских институтов и высших учебных заведений, способных обеспечить развитие в крае наукоемких промышленных производств. В этот период в Красноярске появились Политехнический институт, Институт цзветных металлов имени М.И. Калинина, Институт физики СО РАН и Институт леса. Исполняя решения правительства и партии по вопросам дальнейшего развития региона, в крае ощущалась большая необходимость в научных кадрах. Требовалось организовать подготовку ученых и исследователей на месте, не ожидая приезжих специалистов из центральной России. Решением кадрового вопроса для дальнейшего роста научного потенциала региона было открытие в Красноярске университета. Рассмотрена проблема становления Красноярского государственного университета в начале 7о-х г2. ХХ в. Одним из активных организаторов университета был физик, академик АН СССР Л.В. Киренский. Исследован комплекс вопросов, связанных с формированием социально-экономических условий в регионе, влияющих на развитие вуза как одного из ведущих научных центров Сибири. Особое внимание уделено проблемам университета в первые годы работы, главными из которых были нехватка учебных площадей для расширения контингента студентов и отсутствие жилья для преподавателей молодого вуза. Невзирая на перечисленные проблемы, университет в последующие годы развивался и процветал. В этом, безусловно, заслуга первого ректора Красноярского университета А.И. Дрокина выпускника Красноярского пединститута. Быстрому развитию вуза также способствовали поддержка партии и правительства края, дальнейший рост промышленности и научного потенциала региона. В 2006 г. Красноярский государственный университет стал базой для создания Сибирского федерального университета.

Ключевъе слова: Красноярский государственный университет, высшие учебные заведения, научные кадры. 


\section{Социально-экономический и гуманитарный журнал Красноярского ГАУ. 2020. №1}

The 50-s and 70-s of XX century were the years of economic growth and prosperity in Krasnoyarsk Region. During this period large industrial enterprises were built in the region, which form the basis of Russian industry today, such as the Krasnoyarsk hydroelectric power station, the Norilsk mining and metallurgical combine, and the Krasnoyarsk aluminum plant named after V.I. Lenin. The network of research institutes and higher educational institutions able to ensure the development of high technical industrial production in the region was expanded. During this period the Polytechnic Institute and the Institute of Non-Ferrous Metals named after M.I. Kalinin appeared in Krasnoyarsk, the Institute of Physics SB RAS and Forest Institute. While fulfilling the decisions of the government and the party on further development of the region, there was a great need in the province for scientific personnel. It was necessary to organize training of the scientists and researchers on the spot, without waiting for visiting specialists from Central Russia. The foundation of the University in Krasnoyarsk was the solution of the personnel question for the further growth of scientific capacity of the region. The problem of foundation of Krasnoyarsk State University at the beginning of the 70 -s of $X X$ century was considered. The physicist, the academician of Academy of Sciences of the USSR L.V. Kirensky was one of active organizers of the University. The complex of the questions connected with the formation of social and economic conditions in the region, influencing the development of higher educational institution as one of leading scientific centers of Siberia was investigated. Special attention was paid to the problems of the University in the first years of work, the main from which were the shortage of educational areas for the expansion of the contingent of students and the lack of housing for teachers of young higher educational institution. Without the regard to listed problems, the University in the next years developed and prospered. Certainly, it was the merit of the first rector of Krasnoyarsk University, A.I Drokin, the graduate of Krasnoyarsk Teacher's College. Fast development of higher educational institution was also promoted by the support of the party and regional government, further growth of industry and scientific capacity of the region. In 2006 Krasnoyarsk State University became the base for the creation of Siberian Federal University.

Keywords: Krasnoyarsk state university, higher educational institutions, scientific personnel.

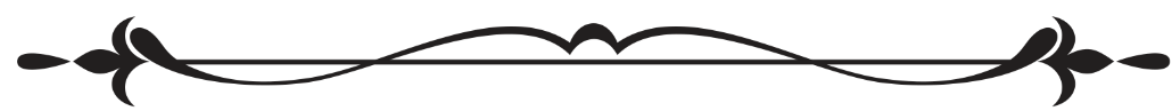

В 2019 г. исполнилось пятьдесят лет с момента образования в Красноярске государственного университета, который стал одним из ведущих вузов страны. Красноярский край в 50-70-е гг. ХХ в. был передовым регионом, получающим преимущественное финансирование, отличающимся высокими темпами экономического развития, ростом городского населения, успешным расширением сети средних специальных и 
высших учебных заведений. На этот период пришлось становление системы научных институтов в крае, что позволило объединить производство и научно-технические достижения, сформировать научную элиту. Цель исследования - раскрыть процесс складывания в Красноярске государственного университета, обозначив успехи и проблемы в первые годы его работы. Исследование основано на документах Государственного архива Красноярского края.

14 января 1969 г. в зале Красноярского театра музыкальной комедии собрались советские и партийные деятели города и края, ученые, преподаватели вузов, студенты, гости из многих городов Советского Союза, которые приехали поздравить наш регион с открытием Красноярского государственного университета. Әто знаковое событие посетили ученые и представители общественности, среди них были ректор и проректор Новосибирского государственного университета, старейшего в Сибири Томского университета, заместитель министра высшего и среднего специального образования РСФСР В.Г. Захаревкий [1, с. 1]. Первым ректором Красноярского университета был назначен д-р физ.-мат. наук, профессор Александр Иванович Дрокин. В этот вечер он со своими коллегами принимал поздравления от участников торжества.

Открытие в Красноярске университета пятьдесят лет назад было действительно знаковым событием, которого ожидали на протяжении почти двух десятков лет. Рост промышленного производства в регионе, бурное развитие машиностроения, черной и цветной металлургии, энергетики и химической промышленности потребовало расширения сети учебных заведений, способных подготовить высококвалифицированных специалистов. Новые промышленные предприятия в крае росли очень быстро. Из доклада председателя оргбюро промышленного крайкома партии В.Ф. Гаврилова (1963 г.): «Увеличилось небывалыми темпами в крае капитальное строительство, прирост промышленной продукции за 4 года составил 50 \%. Введено в строй 353 новых производственных объекта, в городах и рабочих поселках введено в действие жилых домов общей площадью 2700 м². Новыми отраслями промышленности в регионе стали резино-шинная, целлюлозо-бумажная, химико-фармацевтическая» [2, л. 45-47]. Новые промышленные предприятия требовали высококвалифицированных кадров, которых в крае не хватало. Значительная часть специалистов приезжали в Красноярск из Москвы, Ленинграда или других регионов центральной России.

После Великой Отечественной войны в Красноярске действовали три высших учебных заведения - Сибирский лесотехнический институт, Красноярский педагогический и Красноярский медицинский институты. В 50-60-е гг. ХХ в. в городе появилось несколько новых институтов, среди которых были Красноярский сельскохозяйственный институт, Красноярский политехнический институт, Институт цветных металлов имени М.И. Калинина, переведенный из Москвы. Однако правительство было заинтересовано в развитии фундаментальной науки на окраинах Союза, особенно в Сибири. С этой целью в стране расширялась сеть фи- 


\section{Социально-экономический и әуманитарный журнал Красноярского ГАУ. 2020. №1}

лиалов Академии наук, открывались новые университеты. К 1960 г., выполняя решение XXI съезда КПСС, в городе была расширена сеть научно-исследовательских учреждений с 11 до 18 и увеличено количество высших учебных заведений до 6. С 1956 г. в городе работал Институт физики СО РАН СССР, состоящий из пяти лабораторий: физики магнитных явлений, биофизики, молекулярной спектроскопии, эмиссионного спектрального анализа и кристаллофизики. С 1958 г. в Красноярск был переведен из Москвы Институт леса, состоящий из пятнадцати крупных лабораторий [3, л. 7-8]. Научно-исследовательских работников в городе в начале 6о-х гг. XX в. было около 3 тыс. человек, согласно отчетам краевых партийных органов [3, л. 17].

Еще в конце 50-Х гг. ХХ в. появился проект создания университета в Красноярске на базе Красноярского педагогического института. В докладной записке говорилось: «Огромная территория края, несметные природные богатства, быстро растущая промышленность и развивающееся на базе укрупненных колхозов сельское хозяйство требуют, во-первых, научных кадров в самых различных отраслях народного хозяйства, и, вовторых, научного центра, могущего разрабатывать сложные проблемы, как общенаучного характера, так и связанных с развитием края» [4, л. 1]. Также подчеркивалось, что Красноярский педагогический институт обладает достаточным для начала обучения оборудованием по таким специальностям, как физика, химия, ботаника, зоология, геология. Предполагалось, что университет будет организован в составе четырех факультетов: физико-математического (со специальностями физика и математика), историко-филологического, химико-почвенно-биологического (с последующим разделением на факультеты химический и почвенно-биологический) и геолого-географического. Факультет иностранных языков предлагалось выделить в самостоятельный педагогический институт иностранных языков с дополнительным факультетом китайского и немецкого языка [4, л. 1]. Однако этот проект университета не был реализован правительством, вероятно, потому что предложенная структура университета не соответствовала экономическим потребностям региона и лишала край базы для подготовки педагогических кадров.

В 6о-е гг. борьба за открытие университета как фундаментального научно-исследовательского центра края продолжилась. Одним из активных организаторов университета был физик, академик АН СССР, Герой Социалистического Труда Леонид Васильевич Киренский. В своем выступлении на краевой партконференции Киренский говорил: «Красноярский край и в дальнейшем, по-видимому, будет опережать в своем развитии другие края и области Российской Федерации. За это говорят колоссальные природные богатства и неисчерпаемые энергетические ресурсы края. Но при всех этих благоприятных, с точки зрения даров природы, условиях существует серьезное препятствие в освоении богатств нашего края, это необычайно малая плотность населения нашего края, почти в 200 раз меньшая, чем плотность населения Московской области. Таким образом, малым числом людей должны быть подняты 
колоссальные природные богатства, созданы материальные природные ценности. Это возможно только в том случае, если побеждать природу “не числом, а умением”. Сделать это можно, очевидно, только с помощью науки, с помощью механизации как физического, так и умственного труда, с помощью счетно-решающих систем. Край, в котором производительные силы должны развиваться только с помощью самой передовой науки, должен иметь такую науку, ибо развитие науки неотделимо от развития производственных сил» [5, л. 152].

Для развития фундаментальных теоретических научных исследований в крае и формирования научной элиты необходимо было открытие университета. Все институты города готовили выпускников прикладных специальностей, обслуживающих, прежде всего, отрасли растущей краевой промышленности. В Сибири фундаментальная наука еще только зарождалась в этот период. На весь огромный регион было всего 3 университета: в Новосибирске, Томске и Иркутске. Явное отставание высшей школы от потребностей территорий, таких как Красноярский край, Тюменская, Омская и Кемеровская области, заботило партию и правительство. Базой для формирования университета в Красноярске стал филиал Новосибирского государственного университета, который начал работать в городе с 1963 г. [6, с. 351]. В своем выступлении Л.В. Киренский призывал членов краевой партконференции поддержать открытие факультета физики НГУ в Красноярске, подчеркивая, что это приведет к качественному научному росту в крае и решит проблему дефицита научных кадров. «В настоящее время представляется реальная возможность открыть в Красноярске факультет Новосибирского университета. Об этом ходатайствует Научный совет по физике твердого тела при Президиуме Академии наук СССР, это предлагает ректорат Новосибирского университета. Нужно приложить все усилия к тому, чтобы открытие этого факультета было осуществлено в этом году, и чтобы выполнить и перевыполнить план строительства научных учреждений в Красноярске, создать все условия для плодотворной работы ученых, следует раз и навсегда отбросить наивное представление о том, что научные кадры соответствующего качества и в нужном количестве могут быть импортированы из центральных районов страны. Это совсем не так. При распределении студентов физического факультета МГУ в подавляющем большинстве случаев число представителей учреждений, жаждущих получить молодых специалистов, оказывается большим, чем число студентов, распределяемых на работу. В Москве и под Москвой вступают в строй все новые и новые научные учреждения, поглощающие молодых специалистов. Поэтому для обеспечения научными кадрами нашего края кадры эти нужно готовить здесь, на месте» [5, л. 155-156].

Красноярский филиал Новосибирского государственного университета (КФ НГУ) был открыт в Красноярске в 1963 г. Его главной задачей являлась подготовка высококвалифицированных специалистов по специальностям физики и вычислительной математики для научноисследовательских учреждений и промышленности Восточной Сибири и 


\section{Социально-экономический и әуманитарный журрнал Красноярского ГАУ. 2020. №1}

Дальнего Востока. 11 июля 1963 г. начались экзамены на единственный физико-математический факультет КФ НГУ. Первый набор составил 82 человека [7].

Филиал готовил специалистов по физике, математике, биофизике. К 1967 г. набор студентов уже составлял 275 человек. В 1968 г. состоялся первый выпуск филиала - 17 математиков, 13 физиков и 19 биофизиков. Большинство из них были распределены в академические институты Красноярска.

В течение нескольких лет удалось открыть базовые кафедры в Красноярском филиале НГУ, пригласив в город молодых специалистов. Были открыты кафедры: «Общая физика» (заведующий проф. А.Я. Власов), «Математика» (заведующий к.ф.-м.н. B.M. Бусаркин), «Математический анализ» (заведующий канд. физ.-мат. наук Л.А. Азейнберг), «Биофизика» (заведующий проф. И.И. Гительзон), «Основы марксизма-ленинизма» (заведующий канд. физ. наук А.Я. Райбекас). К 1966 г. в филиале уже действовало два факультета - физико-математический и естественный факультет. Возглавляла филиал биофизик Галина Романовна Балуева [7].

Молодые преподаватели поддерживали замысел создателей филиала и ориентировались на создание из студентов не преподавателей и учителей, а ученых. Нормой было развитие в ребятах чувства научного поиска, интереса к самостоятельному приобретению знаний.

Именно на базе филиала НГУ в 1969 г. был образован Красноярский государственный университет. Вся материально-техническая база филиала и студенты были переданы новому вузу. С открытием Красноярского университета кроме подготовки физиков, математиков и биофизиков начался набор студентов на специальности биохимия и юриспруденция. Во вновь созданном вузе в 1970 г. обучалось уже 1200 студентов дневного отделения, 200 - вечернего, 820 - заочного и 100 - подготовительного. Всего 2320 человек. Планировалось, что через несколько лет число студентов достигнет 6 ооо человек [1, с. 1].

Первой большой проблемой молодого вуза была нехватка учебных площадей. Университет разместили в трех зданиях. На пр. Мира-49 работали факультеты юридический и частично математический. Занятия проходили в три смены, потому что у юристов были дневное, вечернее и заочное отделения. В корпусе на ул. Маерчака-6 расположился биологохимический факультет, который в скором времени должен был разделиться на два. Здесь же обучались математики. Там же располагались библиотека, читальные залы, административные службы, НИС и ректорат. В этом же корпусе занимались юристы-вечерники, учащиеся подготовительных курсов и трехгодичной школы математической подготовки инженерного состава промышленных предприятий города. В здании школьного типа, расположенном в Академгородке, проходили обучение студенты физического факультета. Это был единственный факультет, на котором еще можно было увеличить набор студентов, однако в этом же здании располагалась семилетняя общеобразовательная школа, что также приводило к нехватке учебных площадей. На балансе университета 
содержалось лишь одно здание, расположенное по ул. Маерчака-6. Остальные здания университет арендовал. Даже школьное здание в Академгородке, строящееся специально для университета, было передано Горсоветом на баланс городского отдела народного образования [8, л. 9-11].

Ректор университета А.И. Дрокин обращался к администрации города, партийным органам и просил выделить временно с 1971 г. хотя бы одно учебное здание для размещения математического факультета и разгрузки юридического, пока не завершится строительство собственного университетского корпуса. Также он настаивал, что необходимо построить школу в растущем микрорайоне Академгородка и освободить помещение физического факультета.

Второй проблемой университета в первые годы его существования было отсутствие жилья для преподавателей и обслуживающего персонала. А.И. Дрокин писал: «В 1969 г. горсовет выделил университету квартиры для преподавателей с учеными степенями и званиями, прошедшими по конкурсу. В 1970 г. этот процесс замедлился и последовал отказ в выделении жилплощади, хотя ряд приглашенных ученых живут длительный период в гостиницах и на квартирах коллег, не говоря уже о молодых специалистах. Учитывая, что рост нового вуза не может быть осуществлен без привлечения высококвалифицированного состава преподавателей и молодых специалистов, убедительно просим на ближайшие годы увеличить фонд выделяемой университету жилплощади» [8, л. 9-11].

Невзирая на перечисленные проблемы, университет в последующие годы развивался и процветал. В этом, безусловно, заслуга первого ректора Красноярского университета А.И. Дрокина - ученика Леонида Васильевича Киренского, выпускника Красноярского пединститута. Быстрому развитию вуза также способствовали поддержка партии и правительства края, дальнейший рост промышленности и научного потенциала региона. В 2006 г. Красноярский государственный университет стал базой для создания Сибирского федерального университета. Академические традиции продолжаются в стенах СФУ.

\section{Литература}

1. Здравствуй, университет! // Красноярский рабочий. 1969. № 13 (14956) (16 янв.). С. 1.

2. Доклад Председателя оргбюро промышленного крайкома партии В.Ф. Гаврилова // ГАКК (Государственный архив Красноярского края). Ф. П-6693. ОП. 1. Д. 24.

3. Справка о развитие научно-педагогических кадров в г. Красноярске // ГАКК Ф. П-17. Оп. 1. Д. 1945.

4. Докладная записка об открытие в городе Красноярске университета // ГАКК Ф. Р-2217. ОП. 1. Д. 47.

5. Протоколы и стенограммы заседания первой краевой конференции Красноярской промышленной партийной организации и первого 


\section{Социально-экономический и әуманитарный журнал Красноярского ГАУ. 2020. №1}

пленума краевого комитета коммунистической партии Советского Союза // ГАКК Ф. П-6693. ОП. 1. Д. 25.

6. Бъкконя Г.Ф., Федорова В.И., Ценюга С.Н. и др. Очерки по истории народного образования Красноярского края (XVII - начало XXI в.): монография. Красноярск: КГПУ им. В.П. Астафьева, 2014. 580 с.

7. Смотрицкий В.Я. Красноярскому государственному университету четверть века. Исторический очерк // Университетская жизнь. 1994. 17 марта. С. 4-5.

8. Материалы по строительству Красноярского госуниверситета // ГАКК. Ф. 1386. Оп. 1. Д. 4215.

\section{Literatura}

1. Zdravstvuj, universitet! // Krasnojarskij rabochij. 1969. № 13 (14956) (16 janv.). S. 1.

2. Doklad Predsedatelja orgbjuro promyshlennogo krajkoma partii V.F. Gavrilova // GAKK (Gosudarstvennyj arhiv Krasnojarskogo kraja). F. P-6693. Op. 1. D. 24.

3. Spravka o razvitie nauchno-pedagogicheskih kadrov v g. Krasnojarske // GAKK F. P-17. Op. 1. D. 1945.

4. Dokladnaja zapiska ob otkrytie $\mathrm{v}$ gorode Krasnojarske universiteta // GAKK F. R-2217. Op. 1. D. 47.

5. Protokoly i stenogrammy zasedanija pervoj kraevoj konferencii Krasnojarskoj promyshlennoj partijnoj organizacii i pervogo plenuma kraevogo komiteta kommunisticheskoj partii Sovetskogo Sojuza // GAKK F. P-6693. Op. 1. D. 25.

6. Bykonja G.F., Fedorova V.I., Cenjuga S.N. i dr. Ocherki po istorii narodnogo obrazovanija Krasnojarskogo kraja (XVII - nachalo XXI v.): monografija Krasnojarsk: KGPU im. V.P. Astaf'eva, 2014. 580 s.

7. Smotrickij V.Ja. Krasnojarskomu gosudarstvennomu universitetu chetvert' veka. Istoricheskij ocherk // Universitetskaja zhizn'. 1994. 17 marta. S. 4-5.

8. Materialy po stroitel'stvu Krasnojarskogo gosuniversiteta // GAKK. F. 1386. Op. 1. D. 4215.

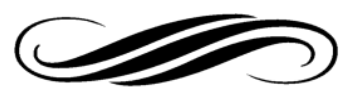

